https://helda.helsinki.fi

\title{
Barriers against wear affect the spatial distribution of tree saplings in urban woodlands
}

\section{Lehvävirta, S.}

Elsevier $\mathrm{GmbH}$

2004

Lehvävirta, S., Rita, H. and Koivula, M. 2004. Barriers against wear affect the spatial

pÿdistribution of tree saplings in urban woodlands. Urban Forestry \& Urban Greening 3: 317.

http://hdl.handle.net/1975/243

Downloaded from Helda, University of Helsinki institutional repository.

This is an electronic reprint of the original article.

This reprint may differ from the original in pagination and typographic detail.

Please cite the original version. 


\title{
Barriers against wear affect the spatial distribution of tree saplings in urban woodlands
}

\author{
Susanna Lehvävirta*, Hannu Rita, Matti Koivula \\ Department of Ecology and Systematics, Division of Population Biology, University of Helsinki, P.O.B. 65, FIN 00014 Helsinki, \\ Finland
}

Received 16 June 2003; accepted 28 October 2003

\begin{abstract}
In order to maintain indigenous, self-regenerating tree populations in urban woodlands, it is essential to identify factors affecting the survival of tree seedlings and saplings. In densely populated areas, intensive recreational use may cause considerable wear of the vegetation and soil, and decrease the total number of saplings. At the same time trees, high stones and other structural elements in a woodland patch can act as natural barriers and give shelter against wear. Hence, we hypothesised that with an increasing amount of wear, a greater proportion of tree saplings survive, and is thus found, close to these natural barriers. We tested this hypothesis with observational data, and described the microhabitat associations of different sapling species in detail to define the most favourable or unfavourable microhabitats. We recorded the microhabitats of saplings and randomly chosen points in 30 medium-fertile Picea abies dominant woodlands in Helsinki and the surroundings, Finland. The description included location in relation to physical objects (stones, trees, topography, etc.), other saplings, vegetation and canopy. We then compared the sapling microhabitats to those available (the random points). Our results suggest that the microhabitat associations of saplings change with increasing wear: Sorbus aucuparia, Populus tremula, Rhamnus frangula, Picea abies and Acer platanoides saplings grew more often close to natural barriers (obstacles $\geqslant 30 \mathrm{~cm}$ high excluding other saplings), the first three showing a statistically significant response to wear in logistic regression models. The saplings were able to grow in a variety of microhabitats, but the species also differed in their microhabitat associations. In general, saplings grew in groups, and in worn sites the grouping was more pronounced. With increasing wear the saplings associated more positively with trees, canopy cover and lush vegetation.
\end{abstract}

(C) 2004 Published by Elsevier GmbH.

Keywords: Indigenous tree species; Micro-sites; Regeneration niche; Trampling; Urban forestry; Boreal; Odds ratios

\section{Introduction}

Urban woodlands are patches of forest vegetation located within or close to an urban settlement. They provide various amenities, including physical (e.g. pollution and noise abatement), recreational, social and cultural values. Environmental psychologists have

\footnotetext{
*Corresponding author.

E-mail address: susanna.lehvavirta@helsinki.fi (S. Lehvävirta).
}

shown that green areas promote mental and physical health (Kaplan and Kaplan, 1989). An everyday pleasure for many citizens is an outing in the green surroundings of their homes. However, not all activities are efficiently guided by a maintained trail network, and people frequently leave the trails (Kellomäki, 1977; Tonnesen and Ebersole, 1997).

While being a pleasure for people, off-trail activities may change the woodland ecosystem through the effects of wear. Recreational use causes compaction and 
erosion of soil, changes in hydrological properties of the soil, and decrease in the cover and biomass of vegetation (Liddle, 1997). Wear also decreases the regeneration success of trees (Tonnesen and Ebersole, 1997; Bhuju and Ohsawa, 1998; Lehvävirta and Rita, 2002). Lehvävirta (1999) suggested that structural elements (e.g. stones, thickets of small trees, fallen logs) may act as natural barriers against wear in urban woodland sites in the Greater Helsinki area, where path cover was high (mean 13\%). Indeed, Tonnesen and Ebersole (1997) found that tree saplings survived better where there was shelter against wear, in a North American PinyonJuniper urban woodland.

The small-scale heterogeneity of the forest floor offers a variety of microhabitats for tree seedlings to establish and grow, called 'safe sites' (Harper, 1977). For example, characteristics such as canopy gaps and fallen logs have been found to be favourable for a range of tree species in a variety of forest ecosystems (Hytteborn et al., 1987; Platt and Strong, 1989; Kuuluvainen, 1994; Kubota and Hara, 1996), but descriptions of the structure of optimal microhabitats are rare (but see Tonnesen and Ebersole, 1997). Furthermore, the characteristics of microhabitats may change as a result of wear: a gap in a countryside forest offers light and growing space, while a similar spot in an urban setting may be intensively trampled. In urban woodlands, saplings in gaps may be killed by wear, whereas saplings close to large trees, if they can endure shade and competition, may survive as they escape trampling.

The question of the effect of wear on the occurrence of saplings in different microhabitats is important because it provides insight into the future regeneration and development of a woodland patch. Wear, together with the supply of natural barriers, may present a selection pressure upon the tree seedlings and saplings: those species or individuals that can grow close to barriers against trampling can be hypothesised as forming the future canopy. This may suggest different management strategies (for example, provision of suitable regeneration sites for preferred tree species) to direct the development of a woodland patch according to societal needs (be it recreational, aesthetic, nature conservation or other).

We used observational data to test the hypothesis that with increasing wear a greater proportion of saplings grows close to barriers against trampling. Our model of sapling survival in relation to wear and the barriers was as follows:

(1) Wear decreases the total number of saplings in a woodland patch.

(2) Trees, high stones and other structural elements in a woodland patch can act as natural barriers against trampling and provide protection against wear.
(3) Hence, with increasing amount of wear, tree saplings are more likely to survive close to these barriers (and are thus found there).

As relatively little is known about the microhabitat requirements of different sapling species, we did not test detailed hypotheses about species-specific survival close to different kinds of barriers. Instead, we described the microhabitat associations of saplings in urban woodlands by exploring the data with a posteriori methods.

\section{Material and methods}

\section{Operationalisation}

We focused on tree saplings $30-200 \mathrm{~cm}$ in height, and classified larger regrowth as trees. Since saplings of different species have different microhabitat requirements, they may vary in the ability to utilise the protection provided by barriers. Because of this, we studied each species separately.

We defined all measurable objects (except saplings) with a minimum height of $30 \mathrm{~cm}$ as potential barriers against wear. Saplings within a $50-\mathrm{cm}$ distance from such a barrier were considered to be growing beside it. As the spatial distribution of saplings in relation to barriers can be expected to depend on the availability of the barriers, we needed an estimate of their supply. Therefore, we used random observation points which we designated as being located beside a barrier or not, like the saplings.

To explore the favourable and unfavourable microhabitats, the close surroundings of each sapling was described in detail. The microhabitat of a sapling was defined as a circle with a $50 \mathrm{~cm}$ radius from the base of the sapling. The $50 \mathrm{~cm}$ radius was assumed to be a suitable distance to measure the effect of barriers against trampling, a possible "avoidance distance" for people from barriers. The description of microhabitat characteristics included vegetation, and the location of the sapling in relation to different objects such as trees, stones, paths, etc. (Appendices A and B). Again, we gave the random points similar descriptions as for the saplings, to generate the expected distribution for saplings in different microhabitats under randomness.

Finally, we defined path cover ( $\%$ of the total area) and indices created by (cover $\times$ visually estimated level of wear) as measures of wear (Appendices A and B, Lehvävirta, 1999). We have used this method of visual estimation of the level of wear in other studies as well, and found that the visual estimation is quick, and corresponds well with the actual number of trespasses (manuscript in preparation). 


\section{Study sites, design and measurements}

The data were collected from July to August 1997 in Helsinki and Vantaa, from an area of $401 \mathrm{~km}^{2}\left(60^{\circ} \mathrm{N}\right.$, $24^{\circ} \mathrm{E}$, Finland), with 711000 inhabitants (Helsinki Region Statistics, 1998). We located medium fertility (Myrtillus-type), spruce-dominant, mature woodland sites on coarse or semi-coarse moraine, with minimal management impact. For the location we used the cities' forest inventory data and field evaluation, and accepted 30 forest compartments (that filled the above criteria), covering different areas of the cities, as study sites (Lehvävirta and Rita, 2002).

The dominant trees in the sites were Picea abies (L.) Karsten and Pinus sylvestris L. with a mixture of Betula pendula Roth and B. pubescens Ehrh., and occasionally other deciduous species. The trees were 85-100 years old, with a mean diameter at breast height (dbh, at $1.3 \mathrm{~m}$ ) of $24-55 \mathrm{~cm}$, a stem density of $70-570 /$ ha and a basal area of $8-26 \mathrm{~m}^{2} /$ ha. The area of the study sites varied between 0.2 and 2 ha according to the size of the forest compartments.

We made all the measurements in five to eight random plots $(5 \times 6 \mathrm{~m})$ per site, except for saplings and small trees ( $<2 \mathrm{~cm} \mathrm{dbh)} \mathrm{of} \mathrm{Sorbus} \mathrm{aucuparia} \mathrm{L.,} \mathrm{which} \mathrm{were} \mathrm{so}$ numerous that we used a subplot of $1 \times 5 \mathrm{~m}$ for them. In sites that were too small for eight plots, we fitted as many as possible, at least five. The sample plots were placed at least $5 \mathrm{~m}$ from each other and from the site edge, except for the narrowest sites where the minimum distance from the edge was occasionally $4 \mathrm{~m}$.

In the sample plots, we recorded the species of all living saplings, and also dead ones if we could identify the species. Shoots growing within a $50 \mathrm{~cm}$ distance from each other were treated as one individual, if a common base could be detected. We described the location of all the saplings and 10 random points in relation to barriers, plus the further microhabitat characteristics (Appendices A and B). We measured path area in each plot with a measuring tape: length $\times$ width of obvious paths and all areas with visible signs of trampling (footprints, broken shoots, torn leaves, etc.), and classified the areas according to the level of wear (Appendix A, Lehvävirta, 1999).

\section{Statistical analyses}

\section{Hypothesis testing}

We used logit models (Collett, 1991) with sample plots as observational units, to test the hypothesis that the proportion of saplings close to barriers would increase with increasing path cover. For each sapling species, the response variable was measured as the proportion of saplings beside a barrier, against the total number of saplings in a sample plot. The path cover $(\%)$ per sample plot was used as the independent variable. To adjust for the effect of the amount of shelter, the proportion of random points beside barriers was submitted to (empirical) logistic transformation and used as an offset variable (Collett, 1991). The ranges of the response variables and path areas are given in Table 1.

Only those species that were observed in at least 20 sample plots were used in the analysis. In addition, plots with no saplings of the focal species were excluded, as the proportion of saplings close to barriers could not be measured. B. pendula was not used in the logit models because of little variation in path area between sample plots in which it occurred (maximum path cover was only $24 \%$ ).

To include the plots with no saplings of the focal species into the analysis we needed another approach. If our hypothesis about the positive effect of barriers and negative effect of wear were true, we

Table 1. The effect of path cover on the location of saplings in sample plots ${ }^{\mathrm{a}}$

\begin{tabular}{lrlllllllr}
\hline Species & Coeff $^{\mathrm{b}}$ & $\mathrm{OR}^{\mathrm{c}}$ & $\mathrm{CI}$ & $p$-value & $n$ & $\mathrm{~min} /$ & $\mathrm{med} /$ & $3 \mathrm{rdq}^{\mathrm{d}} /$ & $\mathrm{max} \mathrm{path} \mathrm{cover}(\%)^{\text {CI }}$ \\
\hline Acer platanoides & 0.39 & 1.49 & $0.79,2.78$ & 0.107 & 44 & $0 /$ & $6 /$ & $10 /$ & 74 \\
Betula pubescens & -1.44 & 0.24 & $0.13,0.44$ & $0.000^{\mathrm{e}}$ & 53 & $0 /$ & $6 /$ & $10 /$ & 43 \\
Picea abies & 0.21 & 1.23 & $0.78,1.94$ & 0.182 & 74 & $0 /$ & $5 /$ & $9 /$ & 49 \\
Populus tremula & 0.34 & 1.40 & $1.17,1.68$ & 0.000 & 86 & $0 /$ & $7 /$ & $12 /$ & 91 \\
Rhamnus frangula & 0.81 & 2.24 & $1.39,3.62$ & 0.001 & 22 & $0 /$ & $6 /$ & $10 /$ & 53 \\
Sorbus aucuparia & 0.28 & 1.32 & $1.13,1.55$ & 0.000 & 130 & $0 /$ & $6 /$ & $14 /$ & 100 \\
\hline
\end{tabular}

The estimates are based on logit model ( ${ }^{\mathrm{e}}$ ), see text. Random points were included as an offset-variable, $p$-values are for one-sided Wald test.

${ }^{\mathrm{a}} \operatorname{logit}(\pi)=\alpha+$ empirical logit(RANBEBAR $)+\beta$ PATHCOVER, where $\pi=$ the proportion of saplings beside barriers, RANBEBAR is the proportion of random points beside an obstacle at least $30 \mathrm{~cm}$ high and PATHCOVER is the area of footpaths, per sample plot.

${ }^{\mathrm{b}}$ Coeff gives the coefficient of path cover in the model, scaled to characterize the effect of a 10 percentage increase in path area. (This corresponds to e.g. $1 \mathrm{~m}^{2}$ increase within a $10 \mathrm{~m}^{2}$ plot, e.g. from 2 to $3 \mathrm{~m}^{2}$ or 7 to $8 \mathrm{~m}^{2}$.)

${ }^{\mathrm{c}}$ Odds ratio, $\mathrm{OR}=\exp ($ Coeff $)$.

${ }^{\mathrm{d}}$ The third quartile.

${ }^{\mathrm{e}}$ Note that the value here, as an unexpected (negative) result of a one-sided test, is not an estimate of type one error but just a probability indicating how likely it would be to get this kind of a sample if the saplings were distributed randomly in relation to barriers. 
would expect (1) fewer saplings with increasing wear and (2) the effect of barriers to depend on the general level of wear. With a small path area, the barriers may have no obvious effect, or the effect may even be negative through a decrease in available growing space. However, with increasing wear, the effect of barriers should become increasingly positive (or at least less negative). This implied a positive interaction between the amount of barriers and wear. (Note that according to our hypothesis path area should be negatively correlated with amount of barriers within a sample plot. To avoid this confounding, we used path cover per study site as the measure of wear, and the proportion of random points beside barriers per sample plot to describe the amount of shelter.) We tested this with Poisson regression (Christensen, 1990), including the above explanatory variables and their interaction in the model. The response variable was the total number of saplings in a sample plot. The analyses for the logitand Poisson-models were made using Statistix for Windows 7.

\section{Exploration}

The purpose of the data exploration was to describe the microhabitats that are available (through random points), and where the saplings of different tree species actually grow in urban woodlands. We also wanted to discover the microhabitat characteristics that are most affected by wear. The effect of wear was explored at the study site level (WIC), sample plot level (WIP), and at the level of individual observation points (saplings and random points, WI and PATHM and PATHS; see Appendix A). From here onwards we refer to the study sites with a wear index WIC $\geqslant 150$ "worn" and those with WIC $<150$ "less worn". The index value of 150 was chosen to represent the most worn sites, but still included approximately $10 \%$ of the sapling observations to allow for description of sapling micro-sites in worn sites.

We applied detrended correspondence analysis (DCA; Jongman et al., 1995) by using CANOCO 4.0 software (Ter Braak and Smilauer, 1998). The dataset consisted of individual observation points (saplings and random) as samples, described by several microhabitat characteristics (Appendix A). We used only characteristics with at least $5 \%$ of the cases larger than zero (Appendix A). Furthermore, we excluded the most scarce sapling species, because of otherwise serious problems with stability of the canonical axes. With these amendments, we had a total of 4420 samples, of which 584 had a WIC value higher than 150 (the most worn sites), representing nine species and the random points.

We also explored the odds ratios (OR) for sapling microhabitat associations, for all the observations per species pooled, separately for worn and less worn sites. The odds ratios are a means of comparing two samples of binary observations (Collett, 1991). In general,

$\mathrm{OR} s=[(s /(1-s)) /(r /(1-r))]$,

where ORs is the Odds ratio for saplings, $s$ is proportion of saplings found in the focal microhabitat of the total number of saplings of the species, and $r$ is proportion of random points found in the microhabitat of the total number of random points, in the study sites where the sapling species in question was found.

A microhabitat with OR $>1$ is "favourable" in the sense that a larger proportion of the saplings is located there than could be expected by the supply of that microhabitat. "Unfavourability" corresponds to $\mathrm{OR}<1$.

\section{Results}

\section{Effect of wear on the location of saplings}

The results for the effect of wear on the location of saplings in relation to barriers are shown in Table 1. The results for Populus tremula L., Sorbus aucuparia and Rhamnus frangula $\mathrm{L}$. were statistically significantly in accordance with our predictions, showing an increasing proportion of saplings close to barriers with increasing wear. Also results for P. abies and Acer platanoides L. showed a similar trend, but were not statistically significant (with a 5\% maximum type I error risk for one-tailed testing). The effect sizes for wear were estimated to be notable. For example, logit-transformed probability that a $P$. tremula sapling is located beside a barrier will increase 0.33 units for a $10 \%$ unit increase in path cover. The odds connected with this probability will correspondingly increase 1.4 -fold. This means, for example, that for the median value of $44 \%$ of $P$. tremula saplings beside a barrier, an increase of 10 percentage units of path cover would lead to a situation where $52 \%$ of $P$. tremula would grow beside barriers.

However, the results for $B$. pubescens were unexpected, with a large negative coefficient, which was very unlikely under the statistical null hypothesis $\mathrm{H}_{0}$ : coefficient $=0$. The reason for this became clear during data exploration. The best microhabitats for B. pubescens were either not included in the "barrier" variable (low stumps), or were completely absent in the worn sites (small trees with dbh $1-9 \mathrm{~cm}$ of Betula spp., $P$. tremula and the "other species" group).

As hypothesised, the Poisson-regression coefficients were negative for the effect of path area, and positive for the effect of barriers and the interaction term (Table 2). The interaction coefficient suggests that, at most, the effect of wear could be reduced by $50 \%$, by increasing the amount of barriers. 
Table 2. Results for the Poisson regression (see text) for the total number of saplings per sample plot

\begin{tabular}{lrl}
\hline Independent variable & Coeff & $p$-value \\
\hline Path cover per study site & -0.02 & 0.000 \\
Proportion of random points & 0.43 & 0.000 \\
$\begin{array}{l}\text { beside a barrier } \\
\text { Interaction }\end{array}$ & 0.01 & 0.023 \\
\hline
\end{tabular}

Path area as percentages. $n=214$.

${ }^{\mathrm{a}} p$-values for one-sided test.

\section{Characteristics of the woodland patches}

Our study sites had a high canopy cover $(85 \%$ of the random points fell under the canopy), and a varying vegetation from barren microhabitats $(21 \%$ of the random points) to those with full field and bottom layer cover $(51 \%)$. Altogether $13 \%$ of the random points were on, and $15 \%$ beside ( $<50 \mathrm{~cm}$ from) paths. The most common structural objects as microhabitat characteristics were other saplings (30\%) and living trees (34\%), the largest proportion of both being $S$. aucuparia. Of the microhabitats, $18 \%$ included stones and $11 \%$ coarse woody debris (CWD) with decay class 2-5 (classes defined in Appendix A). Only $30 \%$ of the gap microhabitats contained a barrier, though $46 \%$ of those microhabitats under the canopy did.

The supply of microhabitats in the worn study sites (WIC $>150)$ differed from that of the less worn sites (Table 3; Appendix B). In the worn sites there were more microhabitats with strong wear and stones, and less microhabitats with full vegetation, small trees (dbh $<10 \mathrm{~cm}$ ), saplings and CWD.

The two first axes in the DCA had eigenvalues of 0.37 and 0.26 (total inertia 3.40), explaining altogether $18.0 \%$ of the variation in the dataset. In the DCA, the majority of the sample and the microhabitat characteristic scores scattered approximately from lower left to upper right (Figs. 1 and 2). The deciduous-tree characteristics were mainly to the left. Populus tremula (POP) and Sorbus aucuparia (SOR) aggregated upwards and to the left, and stumps downwards and to the left. The optima of downed and decaying logs were downwards and to the right, in the direction of the third scatter of samples where wear index (WI) was usually zero. Characteristics reflecting wear (the PATH variables, and possibly also STO1-19 and STODSUM) were upward and to the right.

\section{Overall patterns between saplings and microhabitat characteristics}

The saplings were found in a large variety of microhabitats of varying quality. The lengths of the
DCA gradients for the saplings indicated that, within any of the plotted species' saplings were sometimes found in habitats with only a few characteristics in common with the other ones (Figs. 1 and 2). However, the scores of the saplings (especially Betula spp. and $P$. sylvestris) were, on average, to the left of the randompoint score scatter (Figs. 1 and 2, right).

We divided the DCA sample-score scatter into quarters according to the centre of all of the scores (Figs. 1 and 2). $75.9 \%$ of the random points scattered to the upper-right quarter (Fig. 1a). Compared with these, P. tremula (Fig. 1c), A. platanoides (Fig. 1f) and the other species' group (Fig. 1f) were more to the upper-left quarter - close to the centroids of microhabitats with deciduous trees-having $55 \%$ and $54 \%$ of the samples in that quarter, respectively. B. pubescens scores (Fig. 1d) were aggregated more to the lower left quarter $(69 \%)$, still close to the deciduous tree variables, but also in the direction of microhabitats with stumps. $S$. aucuparia, $P$. tremula and the two coniferous species (Figs. 1b, c, e) had three main scatters: upper left (the direction of deciduous trees and SOR and POP variables), lower right (the direction of DOW variables) and from lower left (microhabitats with stumps) to upper right (the direction of paths, stones and conifers).

The odds ratios (OR) also revealed considerable variation in the microhabitat associations of different species, as well as some similarities (Table 3; Appendix B). The saplings showed least differentiation in their ability to grow on paths and alone with "no saplings" (always strong negative association), in their association with highly decayed stumps (slightly positive or indifferent), as well as with small stones (negative to indifferent) and saplings of other species (slightly negative to slightly positive). The saplings showed most differentiation in relation to fallen logs, snags and living trees.

The species least able to grow under the canopy were P. sylvestris and Salix caprea L. Yet $20 \%$ of P. sylvestris and $61 \%$ of $S$. caprea saplings grew under the canopy, and as much as $85 \%$ of the rest of the saplings did so. In the worn sites, the saplings grew more often under the canopy and in full vegetation than in the less worn sites.

Though the saplings almost never grew on paths, many species often grew beside paths. In general, the saplings were negatively associated with stone surroundings, and only 10 saplings in total were found on top of stones. However, in worn sites, Picea abies associated positively with stony microhabitats (Table 3; Figs. 1e, 2).

In the less worn sites, the saplings were positively associated with stumps and highly decayed coarse woody debris (CWD H; Appendix A), the most favourable microhabitat being the surroundings of old stumps. In the worn sites, the surroundings of stumps 
Table 3. The odds ratios (OR) for saplings for the whole dataset pooled

\begin{tabular}{|c|c|c|c|c|c|c|c|c|c|c|c|c|c|c|c|c|}
\hline \multirow[b]{2}{*}{$n$ for saplings ${ }^{\prime}$ microhabitats } & \multicolumn{11}{|c|}{ Less worn sites, wIC $<150$} & \multicolumn{5}{|c|}{ Worn sites, WIC $\geqslant 150$} \\
\hline & Rand & $\begin{array}{l}\text { Acer } \\
\text { plat } \\
203\end{array}$ & $\begin{array}{l}\text { Betu } \\
\text { pend } \\
93\end{array}$ & $\begin{array}{l}\text { Betu } \\
\text { pube } \\
350\end{array}$ & $\begin{array}{l}\text { Pice } \\
\text { abie } \\
239\end{array}$ & $\begin{array}{l}\text { Pinu } \\
\text { sylv } \\
41\end{array}$ & $\begin{array}{l}\text { Popu } \\
\text { trem } \\
715\end{array}$ & $\begin{array}{c}\text { Prun } \\
\text { padu } \\
41\end{array}$ & $\begin{array}{l}\text { Rham } \\
\text { fran } \\
55\end{array}$ & $\begin{array}{c}\text { Sali } \\
\text { capr } \\
35\end{array}$ & $\begin{array}{l}\text { Sorb } \\
\text { aucu } \\
399\end{array}$ & Rand & $\begin{array}{l}\text { Pice } \\
\text { abie } \\
28\end{array}$ & $\begin{array}{l}\text { Poput } \\
\text { rem } \\
47\end{array}$ & $\begin{array}{l}\text { Rham } \\
\text { fran } \\
15\end{array}$ & $\begin{array}{l}\text { Sorb } \\
\text { aucu } \\
121\end{array}$ \\
\hline CANOOPY & 6.2 & 0.8 & 0.8 & 0.6 & 1.4 & 0.1 & 0.8 & 7.7 & 8.5 & 0.3 & 1.0 & 1.5 & 0.7 & 4.2 & $\infty$ & 1.6 \\
\hline VEGET & 1.3 & 0.6 & 1.3 & 1.4 & 0.3 & 4.6 & 1.0 & 0.5 & 0.1 & 2.2 & 1.0 & 0.3 & 5.4 & 1.6 & 4.0 & 1.4 \\
\hline ON PATH & 0.1 & 0.0 & 0.0 & 0.0 & 0.0 & 0.0 & 0.0 & 0.0 & 0.0 & 0.0 & 0.0 & 12 & 0.0 & 0.0 & 0.0 & 0.0 \\
\hline PATHLM & 0.1 & 0.9 & 0.9 & 0.6 & 0.3 & 2.8 & 0.7 & 0.0 & 1.3 & 1.6 & 1.1 & 1.1 & 0.0 & 1.7 & 2.4 & 1.3 \\
\hline PATHW & 0.0 & 0.0 & 1.7 & 1.2 & 0.0 & 0.0 & 0.1 & 0.0 & 0.0 & 1.2 & 0.2 & 4.9 & 0.3 & 0.9 & 0.7 & 2.5 \\
\hline STO1-39 & 0.1 & 1.2 & 0.4 & 0.1 & 0.5 & 0.5 & 0.7 & 1.5 & 0.3 & 0.3 & 0.9 & 1.5 & 3.0 & 0.7 & 0.0 & 0.4 \\
\hline STO40- & 0.0 & 1.5 & 0.0 & 0.0 & 0.8 & 1.0 & 0.7 & 0.0 & 0.0 & 0.0 & 0.2 & 3.2 & 1.0 & 0.0 & - & 0.1 \\
\hline DEAD & 0.0 & 3.9 & 0.5 & 0.4 & 2.5 & 0.0 & 1.5 & 0.0 & 0.6 & 0.0 & 0.3 & 0.3 & 0.0 & 5.7 & 7.2 & 3.1 \\
\hline DOW & 0.1 & 1.0 & 0.0 & 0.5 & 2.7 & 1.1 & 1.4 & 4.3 & 0.4 & 0.0 & 0.8 & 0.0 & - & - & - & - \\
\hline STUH & 0.1 & 1.4 & 3.1 & 3.7 & 2.3 & 3.9 & 1.2 & 0.8 & 0.8 & 1.6 & 1.7 & 0.6 & 0.0 & 0.0 & 0.0 & 0.3 \\
\hline STUS & 0.0 & 0.8 & 1.0 & 0.2 & 2.1 & 0.0 & 1.9 & 1.2 & 0.0 & 0.0 & 3.5 & 0.2 & - & 0.0 & 0.0 & 0.0 \\
\hline TREOWN1-2 & & 14 & 12 & 24 & 8.6 & - & 5.5 & 39 & 9.6 & 34 & 1.8 & & - & - & 124 & 6.5 \\
\hline TREOTH1-2 & & 2.2 & 1.7 & 3.2 & 0.5 & 1.3 & 0.8 & 0.8 & 1.8 & 0.9 & 1.4 & $0.3^{*}$ & 3.6 & 2.1 & 0.8 & 0.0 \\
\hline TREOWN3-9 & & 3.2 & 0.0 & 5.9 & 4.6 & - & 1.6 & - & - & 19 & 1.3 & & 19 & - & - & 1.2 \\
\hline TREOTH3-9 & & 1.0 & 0.7 & 0.8 & 1.4 & 0.0 & 0.8 & 3.8 & 0.2 & 0.5 & 0.8 & $0.3^{*}$ & 0.0 & 2.4 & 0.0 & 0.0 \\
\hline TREOWN10- & & 0.0 & 0.0 & 1.0 & 1.6 & 0.0 & 3.8 & - & & 0.0 & 1.0 & & 0.0 & 8.9 & & 1.5 \\
\hline TREOTH10- & & 1.1 & 0.1 & 0.3 & 1.5 & 0.0 & 0.6 & 0.4 & 1.2 & 0.0 & 1.6 & $1.3^{*}$ & 2.1 & 0.8 & 4.0 & 1.0 \\
\hline POP3- & 0.0 & 1.3 & 0.0 & 1.1 & 0.0 & - & 2.3 & 0.0 & 1.5 & 0.0 & 2.6 & 0.3 & 5.3 & 8.9 & 35 & 5.7 \\
\hline BUSHES & 0.0 & 0.7 & 0.6 & 0.7 & 0.0 & 0.0 & 0.5 & 0.4 & 0.0 & 0.8 & 0.4 & 0.0 & - & - & - & - \\
\hline SAPLOWN & & 15 & 8.3 & 23 & 11 & 6.5 & 13 & 172 & 138 & 114 & 7.8 & & 35 & 5.5 & 106 & 22 \\
\hline SAPLOTH & & 2.2 & 1.0 & 0.7 & 0.5 & 6.6 & 0.8 & 0.5 & 0.7 & 1.9 & 0.9 & & 0.8 & 1.7 & 1.9 & 0.9 \\
\hline NOSAPLING & 2.1 & 0.1 & 0.3 & 0.1 & 0.5 & 0.1 & 0.2 & 0.2 & 0.2 & 0.2 & 0.2 & 2.1 & 0.1 & 0.1 & 0.1 & 0.1 \\
\hline
\end{tabular}

Odds (not OR) are given for random points (Rand) in the microhabitats in the sites with no to moderate wear (less worn sites). The OR for random points in the worn sites give the ratio between Odds for random points in the worn sites as compared to the less worn sites. Descriptions of the microhabitats are given in Appendix B. $\infty$, is used when all saplings were found in the microhabitat, or when saplings were found in the microhabitat even if random points were not. In both cases the OR is positive, but cannot be counted because of a zero in the denominator; - is used when no saplings nor random points were observed in the microhabitat; ${ }^{*}$, for the random points any tree species were included in the calculations. 

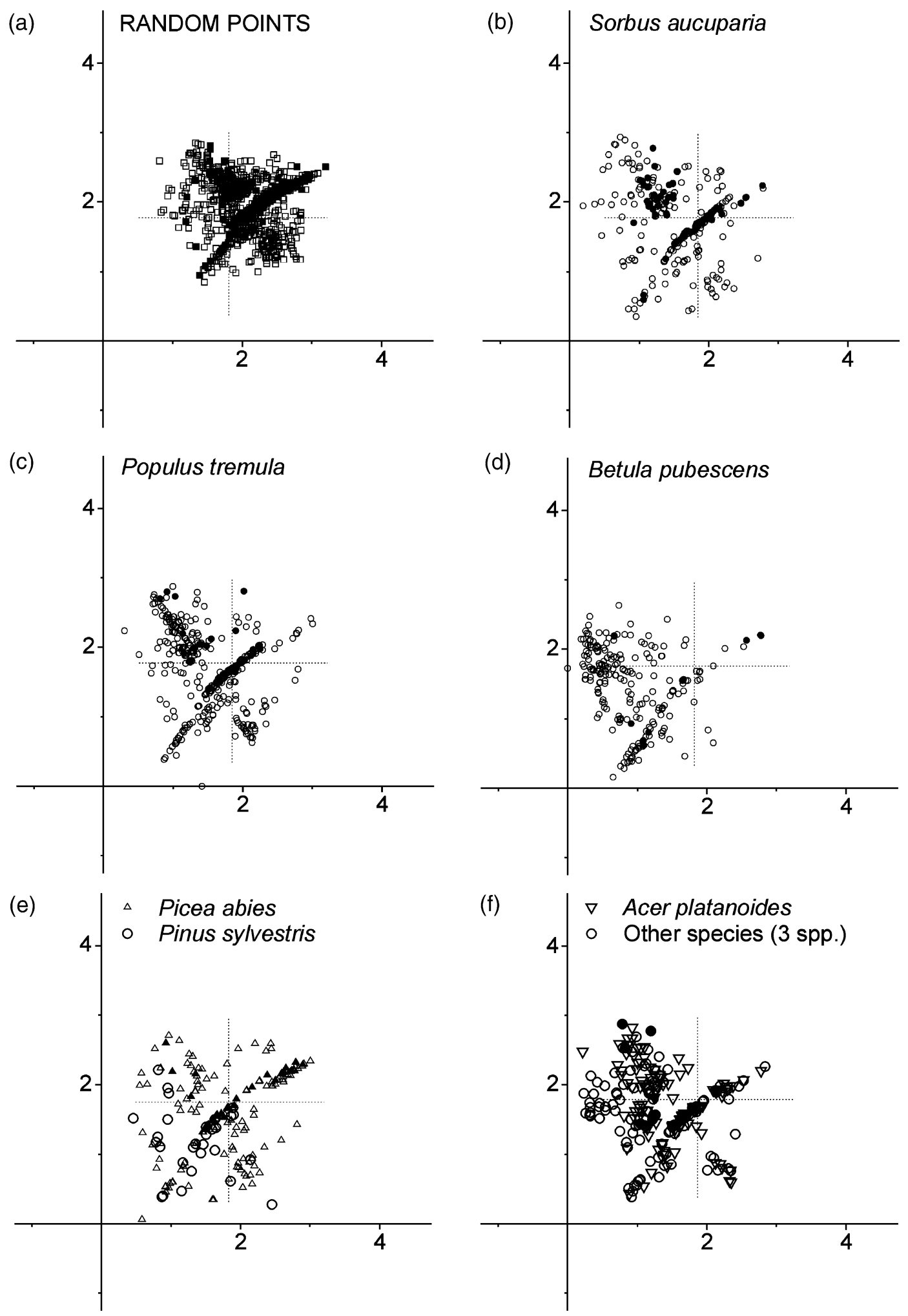

Fig. 1. DCA sample scores for random sampling points: (a) and for the six most abundant tree species (b-f). The scores of the rest of the sapling species are shown with similar symbols (f). Black symbols indicate worn (WIC > 150), and hollow symbols indicate less worn sites. The crossing point of the two perpendicular dash lines shows the centre of the species and random-point scores.

seemed unfavourable, fallen logs were absent and the data showed no general trend in the favourability of snags.
The saplings were strongly positively associated with other saplings, especially with con-specifics. Betula spp., $P$. sylvestris and $S$. caprea formed a positively associated 


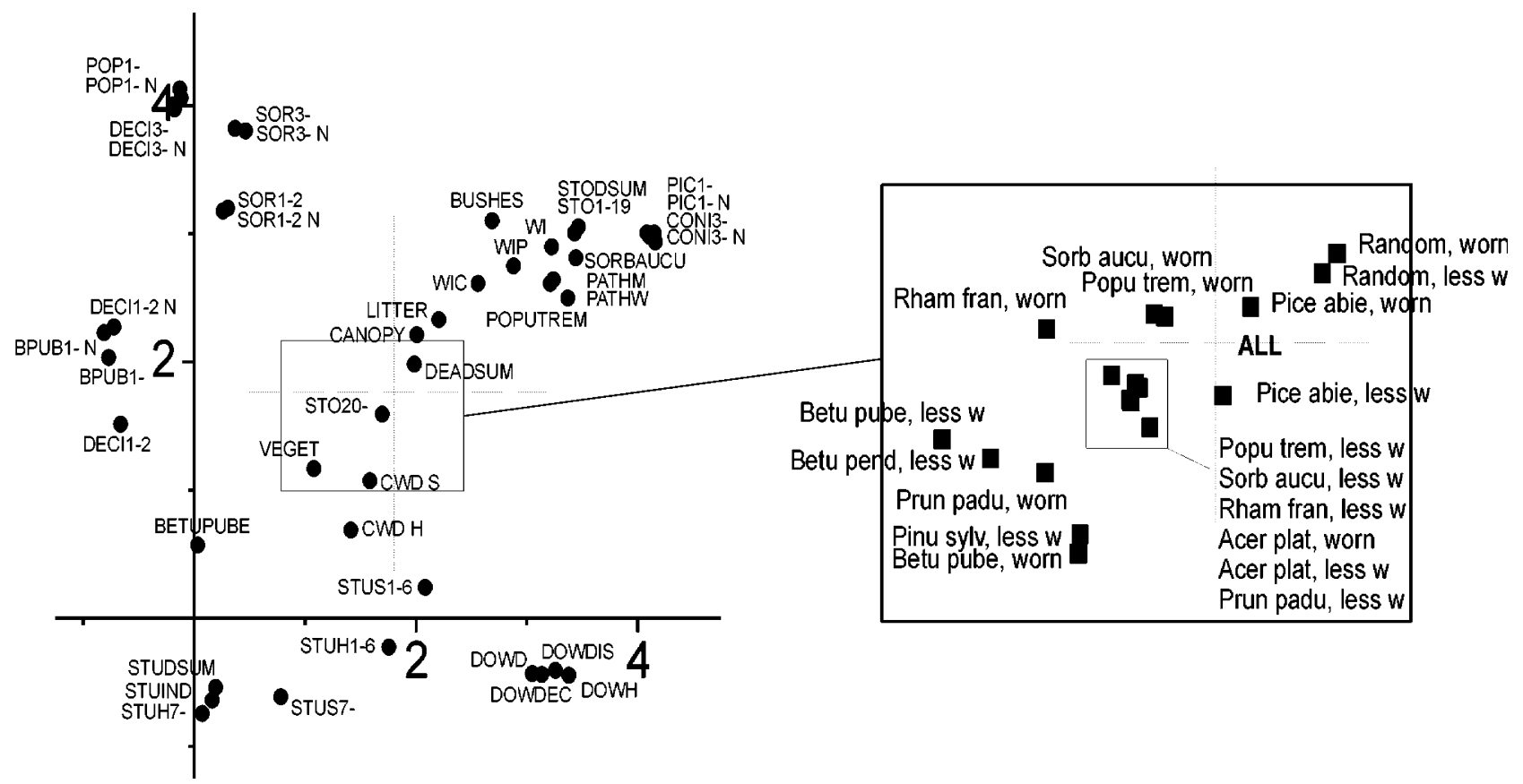

Fig. 2. DCA biplot scores for the variables that determined the growth sites of the tree saplings (see Fig. 1). The crossing point of the two perpendicular dash lines ('ALL' on the right-hand side) show the centre of the species and random-point scores. On the righthand side, the centres of the sample scores of worn ('worn', WIC > 150) and less worn ('less w') sites are shown for the random points and tree species presented in Fig. 1.

group, while Prunus padus L. and $R$. frangula associated mostly negatively with any other saplings but their own species. The saplings were also positively associated with small trees (dbh 1-2 cm), in particular with con-specifics, but grew less often with larger trees $(\mathrm{dbh}>3)$. Among trees, the saplings associated most negatively with A. platanoides and $P$. abies, while the most favourable tree species for saplings may be hypothesised to be $P$. tremula (Table 3) and P. sylvestris (with only 21 sapling and 19 random point microhabitats). In the worn sites, the saplings grew more often beside trees than in the less worn sites (ORs for growing beside a tree, all sapling species pooled, were higher in the worn sites than in the less worn ones).

\section{Species-specific microhabitat associations}

Below, we summarise the exploration results for each species (Table 3 ) and provide information not displayed in the table.

A. platanoides grew slightly more often in gaps than under the canopy, mainly in sparse vegetation. Among the sapling species, it seemed the most tolerant to stoniness. It associated positively with CWD except for fresh small stumps (STUS1-6, Appendix A). It also associated positively with saplings and small trees (dbh $<10 \mathrm{~cm}$ ) of $P$. tremula, as well as with $A$. platanoides and $S$. aucuparia of any size, and large $(\mathrm{dbh}>10 \mathrm{~cm})$ P. sylvestris.

$B$. pubescens and $B$. pendula associated only slightly positively with gaps. The proportion under the canopy, of Betula size classes 30-50, 51-100, 101-150 and $151-200 \mathrm{~cm}$, varied between $74 \%$ and $77 \%$. This implied similar death rate with increasing size under canopy and in gaps. The saplings grew often with small (dbh < $10 \mathrm{~cm})$ Betula spp. individuals, but the surroundings of A. platanoides, S. aucuparia and P. abies individuals of any size seemed unfavourable. In the worn sites, only B. pubescens was found. There it associated positively with the canopy, and less negatively with stones than in the less worn sites. The highly positive association of B. pubescens with stumps in worn sites was much a result of a group of eight individuals around one stump at one study site. In worn sites, $B$. pubescens also associated positively with large $P$. abies $(\mathrm{dbh}>10 \mathrm{~cm})$, and the association with saplings of its own species was even stronger than in the less worn sites.

$P$. abies grew both under the canopy and in gaps, in usually only a sparse vegetation cover (Table 3 ). Of all the saplings it had the strongest positive association with (especially highly decayed) CWD. It also had a positive association with con-specifics of any size, Betula spp. and $P$. sylvestris trees. It had a negative association with small $S$. aucuparia trees (dbh $1-2 \mathrm{~cm})$ and saplings, as well as with $P$. tremula of any size. Of saplings, it associated most positively with $P$. abies, $R$. frangula and 
$S$. caprea. In worn sites, P. abies grew more often in full vegetation, beside small stones and with con-specifics than in the less worn sites.

$P$. sylvestris associated positively with CWD $\mathrm{H}$ and saplings of $P$. sylvestris, Betula spp. and $S$. aucuparia, but extremely negatively with $P$. abies individuals of any size (Table 3, Figs. 1e and 2). It was not found at all close to trees larger than $3 \mathrm{~cm}$ by dbh.

$P$. tremula had a wide amplitude in relation to the canopy, vegetation cover and stoniness (Table 3, Fig. 1c). Microhabitats with woody debris seemed favourable. Of living woody individuals, it associated clearly positively only with con-specifics and small A. platanoides $(\mathrm{dbh}<3 \mathrm{~cm})$. In the worn sites, it grew more often under the canopy, in full vegetation, with small dead trees $(\mathrm{dbh}<6 \mathrm{~cm})$ and living $P$. tremula and $S$. aucuparia saplings and trees. In the worn sites, $P$. tremula also associated strongly positively with $P$. abies saplings.

$P$. padus grew almost always under the canopy, in varying vegetation cover (Table 3). It associated positively with large stumps and fallen trees. It also associated positively with small con-specifics and $S$. aucuparia trees, but it did not grow together with Betula spp. of any size.

Of all the species studied, $R$. frangula grew most often under the canopy and had least vegetation cover in its microhabitats (Table 3). It associated positively with con-specifics and small $S$. aucuparia trees (dbh $1-2 \mathrm{~cm}$ ), but the surroundings of Betula spp. individuals and $P$. abies trees seemed adverse for $R$. frangula. It was the only species with no positive association with any kind of CWD. In the worn sites, it always grew under the canopy and often in full vegetation. There it was also associated positively with small snags $(\mathrm{dbh}<6 \mathrm{~cm})$, living con-specifics, $P$. abies, and large $P$. tremula $(\mathrm{dbh}>10 \mathrm{~cm})$.

S. caprea was the second most intolerant of canopy cover (Table 3), and it associated strongly negatively with stones and CWD (except for highly decayed stumps). It associated negatively with $S$. aucuparia of any size and tree surroundings in general, but positively with Betula spp. saplings.

$S$. aucuparia was the most indifferent sapling species with respect to canopy and vegetation cover (Table 3, Figs. $1 \mathrm{~b}$ and 2). It had a positive association with stumps; both fresh and highly decayed ones. It was among the least positively associated with its own species, but associated positively with $P$. tremula of any size as well as Betula spp. trees larger than $2 \mathrm{~cm}$ by $\mathrm{dbh}$. It was the second most tolerant (after $P$. abies saplings) of large P. abies $(\mathrm{dbh}>10 \mathrm{~cm})$. In worn sites, it associated positively with the canopy, full vegetation cover and snags. There it also had a stronger positive association with its con-specifics, as well as with P. tremula and Betula spp. trees.

\section{Discussion}

We studied tree saplings with a minimum height of $30 \mathrm{~cm}$, as we were not interested in the dispersal dynamics or the initial development of seedlings. Rather, we focused on finding the spots in urban woodlands where tree saplings survive, forming the sapling bank. However, seed dispersal and initial growth determine the "material" on which trampling and barriers can have an effect. This is why we also discuss the favourability of different microhabitat types on the seedling stage whenever we found relevant literature. Further, we stress that there may be important mechanisms worth studying, before the sapling stage, that shape the spatial distribution of saplings.

Our results corroborated the hypothesis of Tonnesen and Ebersole (1997), that under the effect of strong recreational use, tree saplings survive best close to barriers that provide shelter. This implies that in worn woodland patches the future horizontal structure is shaped by wear and the present horizontal structure i.e. the location of barriers. This viewpoint should be brought into discourse with the current approaches of urban forestry.

Tonnesen and Ebersole (1997) suggested the spatial extent of wear to be minimised. This could be done at a small scale, by preserving or providing the type of natural barriers most beneficial for regeneration. We tested both the maximum distance of $50 \mathrm{~cm}$ from the barriers, and the plot area of $30 \mathrm{~m}^{2}$, and found barriers effective at both scales. Study designs that quantify the spatial extent of the effect are necessary to further test and develop the idea of natural barriers as a management tool in urban woodlands, or other heavily used recreational forests.

Although all species here were flexible towards the microhabitat, the future canopy species may still be selected by the supply of barrier types: those able to grow in the range of microhabitats available will form the future canopy ("regeneration niche", Grubb, 1977). This has clear scientific and management implications: the most favourable microhabitats and barriers for a given species need to be recognised to preserve a viable population of that species. This is especially important in urban woodlands, where many factors are suggested to suppress, or alter the species assemblage of the regrowth (Tonnesen and Ebersole, 1997; Bhuju and Ohsawa, 1998; Lehvävirta and Rita, 2002).

Ecological data for non-commercial tree species are rare, but essential if people want to preserve or promote these species in recreational woodlands. Our results for the less worn woodlands can be suggestive for rural areas as well. However, our descriptions of the favourable microhabitats remain hypothetical: the descriptions have not been tested, and may be specific for our data. Furthermore, the structural characteristics used here are 
only one subset of potential microhabitat characteristics: other ones could be soil properties and solar radiation, for example (Collins and Good, 1987; LeDuc and Havill, 1998). Further, as trampling is an essential factor shaping the woodlands, the efficiency of different barriers against it should be tested, for example the barrier height (Lehvävirta, 1999). Yet, our results provide a new perspective and are a good starting point for further, more testing-oriented designs.

\section{The supply and favourability of the microhabitats}

The $50 \mathrm{~cm}$ maximum distance used here was chosen subjectively. The outcome of the microhabitat descriptions is most likely highly dependent on the scale one chooses to use. Here the scale was chosen to evaluate the suitability of different trampling barriers for regeneration, assuming the possible distance of trespasses from barriers to be $50 \mathrm{~cm}$.

The microhabitat supply in the worn sites differed from that of the less worn ones. Due to the rarity of some microhabitats in the worn sites, e.g. fallen logs, we cannot give any data-driven hypotheses about their effects with increasing wear. However, if a microhabitat seems favourable in general and can provide shelter from wear, it can be hypothesised to be favourable also in the worn sites. The results of Tonnesen and Ebersole (1997) support this: Pinus edulis and Juniperus monosperma regrowth persisted in different trampling regimes in microhabitats known to be favourable for them, and giving shelter against wear.

Gaps are emphasised as favourable regeneration spots (Whitmore, 1989; Leemans, 1991; Qinghong and Hytteborn, 1991; Kubota and Hara, 1996) but some studies give examples of random recruitment patterns in relation to the canopy (Ward and Parker, 1989; Kubota, 2000). The use of the concepts "regeneration" and "gap" varies between studies, and results may be difficult to compare. We want to highlight our observation that tree saplings survived well under the canopy. From this sapling bank individuals can grow into the canopy once sufficient growing space becomes available (Sernander, 1936; Wright et al., 2000). In our urban sites, gaps are not a prerequisite nor do they guarantee tree regeneration.

Gap size is proposed to be an essential feature for regeneration success (Qinghong and Hytteborn, 1991; Kuuluvainen, 1994; Beckage et al., 2000; but see Nakashizuka, 1989). We did not consider gap size, as the observation points were simply assigned as being located under the canopy or not (in a "gap"). Although we considered even small canopy openings, our total gap area was modest: only $15 \%$ of the random points were in a gap. These aspects suggest that our result is not comparable with studies concerning the favour- ability of larger gaps, but at the same time further emphasize our conclusion that a sapling bank can persist without large openings in the urban woodlands.

The favourability of gaps also depends on the microhabitat variation within them (Nakashizuka, 1989; Whitmore, 1989; Kuuluvainen, 1994; Beckage et al., 2000; Narukawa and Yamamoto, 2001). Our observation of fewer barriers in gaps, and decreased favourability of gaps and stump surroundings with increased wear suggests that the opening of growing space does not guarantee sapling survival, if no barriers against wear remain. In our sites, uprootings and fallen logs were few, likely because of removal of fallen trees for aesthetic reasons, and because some of the gaps were not created by tree fall.

Ground and field layer vegetation competes with tree seedlings (Yli-Vakkuri, 1963; Collins and Good, 1987; Taylor and Zisheng, 1988; Kuuluvainen, 1994; Kuuluvainen and Juntunen, 1998). However, a poor vegetation cover is often a sign of wear in urban woodlands, and thus not favourable for initial survival, as supported by the result that the saplings had a more positive association with vegetation in worn plots. Further, tree seeds may be washed away from barren spots (YliVakkuri, 1963), and even more so in urban woodlands with compacted soils, hydrophobic surface and probably larger runoff (Liddle, 1997).

Trees and saplings compete with each other (Aaltonen, 1942; Weiner, 1984), yet saplings often grow in dense clusters crowding the favourable microhabitats (Leemans, 1991; Kuuluvainen and Juntunen, 1998). We cannot suggest that the grouping of saplings found in urban woodlands was related to canopy gaps, as Leemans (1991) could for his rural study sites. The generally stronger positive association of saplings with other ones in the worn sites implies that saplings avoid getting trampled upon - and thus survive best - in groups.

Large trees suppress seedlings and saplings by restricting the availability of nutrients, light and moisture (Kalela, 1942; Kuuluvainen et al., 1993; Kuuluvainen, 1994). However, tree roots may be unevenly distributed and some may have a low vigour (Laitakari, 1927). This may leave spots with less root competition, even close to trees, for saplings to thrive. Moreover, different tree species may have different effects e.g. through modification of $\mathrm{pH}$, temperature regime and nutrient, light and water availability or allotoxic effects (Boettcher and Kalisz, 1990; Grubb, 1977). For example, Betula spp. are considered soil improvers (Perala and Alm, 1990; Atkinson, 1992). Here this improvement effect was not visible as an increase in favourability: the immediate surroundings of Betula trees with $\mathrm{dbh} \geqslant 10 \mathrm{~cm}$ did not seem to be better regeneration sites than the surroundings of other tree species. The tentative unfavourability of $A$. platanoides and $P$. abies surroundings might be related to their 
efficient shading and litter attributes. Of all the species here, $P$. tremula offered the most favourable microhabitat for most sapling species, and also $P$. sylvestris can be hypothesised to be favourable for other species.

Fallen trees, uprooting pits and mounds and rotten stumps are found to be favourable for tree regeneration in many ecosystems (Hytteborn et al., 1987; Perala and Alm, 1990; Kuuluvainen, 1994; Kubota and Hara, 1996; Narukawa and Yamamoto, 2001). Our study sites lacked a representative decay succession of uprootings as compared to unmanaged forests (e.g., Leemans, 1991; Qinghong and Hytteborn, 1991; Kuuluvainen, 1994). The well-decayed class 4 and $5 \operatorname{logs}$ that could act as seedbeds (cf. Hofgaard, 1993) were rare (observed at only one per cent of the random points). This may explain the variable results concerning their favourability. Stumps were not numerous either, but large rotten stumps seemed favourable, though they decreased in favourability with increasing wear. Here, most stumps were lower than $30 \mathrm{~cm}$, and likely to be ineffective as barriers. If cuttings are performed in areas with heavy recreational pressure, it could be worth trying whether leaving high $(>150 \mathrm{~cm})$ stumps would provide shelter and enhance seedling and sapling survival.

A high abundance of tree seedlings near rocks was reported during primary succession (Jumpponen et al., 1999) and in pastures (Livingston, 1972), explained by dispersal dynamics. Kuuluvainen (1994) noted that stone surroundings may be less favourable than stump surroundings, e.g. because there is no increase in nutrient availability close to stones. In our data stone surroundings and tops seemed unfavourable, with no general trend of increasing favourability in the worn sites as we expected. Only $P$. abies seemed to benefit from the presence of stones in the worn sites, within the $50 \mathrm{~cm}$ radius used here. Even the high $(\geqslant 40 \mathrm{~cm})$ stones did not offer shelter. Thus, we cannot say, as Tonnesen and Ebersole (1997) did, that rocks could provide refuge from wear.

\section{Microhabitat associations of different species}

The favourability of microhabitats varied between species, implying regeneration niche differentiation (Grubb, 1977), giving way for few generalisations. However, the inability to grow on paths, and a tendency to grow in groups was common for all species.

A. platanoides is usually considered a shade-tolerant species (e.g. Hämet-Ahti et al., 1992), but here it associated positively with both shade-tolerant $(S$. aucuparia and small $P$. abies), and light-demanding species ( $P$. tremula). The association of $A$. platanoides with sparse vegetation may be due to better establishment and survival there, or a result of the leaf litter reducing vegetation cover.
The good survival of Betula spp. saplings under the canopy (until they reach $2 \mathrm{~m}$ ) found here agrees with Perala and Alm (1990), who reported that B. pendula can endure $90 \%$ shade. However, it contradicts Qinghong and Hytteborn (1991) and Hytteborn et al. (1987) who suggested that Betula spp. regenerate only in large gaps. Hytteborn et al. (1987), Perala and Alm (1990), Qinghong and Hytteborn (1991) and Yli-Vakkuri (1963) suggested that Betula spp. grow most abundantly on highly decomposed logs and mineral soil where tree root competition and vegetation cover is reduced. In our study, however, Betula spp. saplings grew often in full vegetation cover, most likely because vegetation was indicative of less wear, and more abundant in gaps. We could not find the positive association of Betula spp. with $P$. sylvestris or $P$. abies reported by Perala and Alm (1990), and we question their interpretation of the results of Aaltonen (1942) that Betula spp. saplings would grow better with saplings of these conifers than with other Betula saplings. However, we found a negative association (throughout the size classes) with A. platanoides similar to that between Betula spp. and Acer saccharum (Perala and Alm, 1990).

P. abies is shade-tolerant (e.g. Hytteborn et al., 1987) and able to survive under the canopy (Kuuluvainen, 1994). Thus, the positive association with canopy we found is no surprise; however, we cannot interpret the negative association with the canopy in the worn sites. In agreement with Yli-Vakkuri (1961) we found a negative association of $P$. abies saplings with full vegetation, but cannot say whether it was the saplings reducing vegetation covering vegetation cover, or unfavourability of full vegetation for seedling establishment. $P$. abies is suggested to regenerate well on decomposed logs (Hytteborn et al., 1987; Kuuluvainen, 1994), and here too associated positively with all kinds of CWD.

Qinghong and Hytteborn (1991) found no clear effect of gaps on regeneration of $P$. sylvestris, and Kuuluvainen (1994) noted that understorey seedlings could live suppressed for several decades underneath old, less vigorous parent trees with damaged root systems. Here however, the competitive weakness of $P$. sylvestris was obvious, it being the species with least saplings under the canopy, and no saplings within the immediate surroundings of trees larger than $3 \mathrm{~cm}$ by $\mathrm{dbh}$. The positive association of $P$. sylvestris with CWD, small Betula spp. and small $P$. tremula, and the relatively high tolerance of vegetation cover in our study parallels previous findings (Carlisle and Brown, 1968; Kuuluvainen, 1994; Jonsson, 1999; Kuuluvainen and Juntunen, 1998).

In forested areas, $P$. tremula regenerates mainly through root suckers, the locations of which are determined by parent trees (Qinghong and Hytteborn, 1991; Greene et al., 1999). This agrees with our results, though our methods may have underestimated the 
aggregation of shoots: we did not note shoots closer than $50 \mathrm{~cm}$ to a parent, if they had a common base with that tree while shoots further away were noted as saplings independent of their origin. According to Jonsell and Karlsson (2000) P. tremula competes successfully with spruce. However, we found the close surroundings of $P$. abies unfavourable for $P$. tremula regrowth.

According to a plot map of Hytteborn et al. (1987) $P$. padus saplings were not confined to gaps or logs. Our results also suggest that $P$. padus grows well under the canopy, but we found a tentative relationship with CWD. Leather (1996) mentions that P. padus often grows together with Betula spp. and S. aucuparia. At the $50 \mathrm{~cm}$ distance we used, we found a tentative positive association of $P$. padus with $S$. aucuparia, but a negative one with Betula spp.

Qinghong and Hytteborn (1991) suggested that $S$. caprea sapling distribution depended on that of the parent trees. We found the saplings associated positively with small to medium-size individuals of its own species. $S$. caprea is considered a pioneer species, and here it appeared with other pioneers, expressly Betula spp. saplings.

Hytteborn et al. (1987) suggested no microhabitat differentiation for $S$. aucuparia, and Backmeroff and Peterken (1988) reported good regeneration and prolonged survival under closed canopy. These parallel our finding that $S$. aucuparia was relatively tolerant of canopy and vegetation cover. The tolerance of a large variety of microhabitats may be due to the regeneration through rootsuckers that are connected to larger trees. Furthermore, as for $P$. tremula, we may have underestimated the aggregation of $S$. aucuparia saplings around its parent trees. S. aucuparia may be the most successful species under heavy recreational use, as it had the highest number of individuals in the worn sites (cf. Lehvävirta and Rita, 2002).

\section{Conclusions}

As the green areas of a city are important for recreation of inhabitants, wear will continue to be an important factor shaping the ecosystems. Therefore, both scientists and urban foresters should keep developing management options to keep the consequences of wear at a minimum.

Based on our results it is easy to agree with Tonnesen and Ebersole (1997), who suggest limiting the extent of areas under strong wear ("sacrifice areas"), as well as preventing further deterioration of less worn areas. Furthermore, we suggest that structural elements of woodlands should be considered as management tools, not just objects.
Preserving or providing a variety of microhabitats that can act as natural movement barriers may promote the diversity of woody regeneration. Management tends to reduce forest structural elements, especially by preventing the creation of CWD. For the tree species we studied gaps are not essential for establishment and initial growth, at least in the urban woodlands. From this point of view the common belief held by urban foresters in Finland that gap creation by logging is necessary for regeneration should be questioned. Instead, a variety of barrier types are needed to promote species diversity in the sapling bank.

Admittedly though, after initial establishment, the promotion of Betula spp., S. caprea and P. sylvestris would require openings in the canopy layer, and especially the felling of $P$. abies, A. platanoides and $S$. aucuparia. On the other hand, the promotion of $P$. abies does not require openings in the canopy (only P. tremula seemed unfavourable to $P$. abies saplings), but logs would provide favourable seedbeds in addition to providing shelter.

In practical terms, we suggest leaving thickets, leaving logs or even cutting down trees to guide peoples' movement, and leaving tall stumps when cuttings are performed in vulnerable areas. We propose studies that focus on the public acceptance of this kind of management strategy. Furthermore, we suggest that in the long term, the effect of such practices on biodiversity should be studied.

\section{Acknowledgements}

This work was financed by ECOPLAN (Project Number 39715) of the Finnish Biodiversity Research Programme FIBRE. Helsinki and Vantaa cities helped in finding appropriate study sites. We are also grateful to Jonna Niemenmaa for assisting with the field work, Renae Stenhouse for checking the language, and Timo Tuomivaara for invaluable guidance in philosophy of science.

\section{Appendix A}

The microsite characteristics recorded for each sapling and random point at a $50-\mathrm{cm}$ radius (unless otherwise stated). For the distance variables, five classes $(0-4)$ were used. $0=$ no object of the kind within the $50-\mathrm{cm}$ radius from the observation point. $1=25$ $50 \mathrm{~cm}$ distance to the object. $2=$ the distance class was missing but known to be 1 or $3.3=$ distance to the object $0-25 \mathrm{~cm} .4=$ location of the observation point on top of or underneath the object. Med = median, Ave $=$ average, $\operatorname{Min}=$ minimum and $\operatorname{Max}=$ maximum values. 


\begin{tabular}{|c|c|c|c|c|c|}
\hline Variable & Description & Med & Ave & Min & Max \\
\hline BUSHES & Distance to the nearest bush $^{\mathrm{a}}$ & 0 & 0.02 & 0 & 3 \\
\hline BETUPUBE & Distance to the nearest Betula pubescens sapling & 0 & 0.02 & 0 & 3 \\
\hline POPUTREM & Distance to the nearest Populus tremula sapling & 0 & 0.04 & 0 & 3 \\
\hline SORBAUCU & Distance to the nearest Sorbus aucuparia sapling & 0 & 0.13 & 0 & 3 \\
\hline BPUB1- & Distance to the nearest Betula pubescens with $\mathrm{dbh} \geqslant 1 \mathrm{~cm}$ & 0 & 0.10 & 0 & 3 \\
\hline BPUB1-N & Number of Betula pubescens with $\mathrm{dbh} \geqslant 1 \mathrm{~cm}$ & 0 & 0.09 & 0 & 11 \\
\hline PIC1- & Distance to the nearest Picea abies with $\mathrm{dbh} \geqslant 1 \mathrm{~cm}$ & 0 & 0.12 & 0 & 4 \\
\hline $\mathrm{PIC} 1-\mathrm{N}$ & Number of Picea abies with $\mathrm{dbh} \geqslant 1 \mathrm{~cm}$ & 0 & 0.08 & 0 & 3 \\
\hline POP1- & Distance to the nearest Populus tremula with $\mathrm{dbh} \geqslant 1 \mathrm{~cm}$ & 0 & 0.07 & 0 & 3 \\
\hline POP1-N & Number of Populus tremula with $\mathrm{dbh} \geqslant 1 \mathrm{~cm}$ & 0 & 0.04 & 0 & 3 \\
\hline SOR $1-2$ & Distance to the nearest Sorbus aucuparia with $\mathrm{dbh} 1-2 \mathrm{~cm}$ & 0 & 0.22 & 0 & 3 \\
\hline SOR1-2 N & Number of Sorbus aucuparia with dbh $1-2 \mathrm{~cm}$ & 0 & 0.16 & 0 & 6 \\
\hline SOR3- & Distance to the nearest Sorbus aucuparia with $\mathrm{dbh} \geqslant 3 \mathrm{~cm}$ & 0 & 0.12 & 0 & 4 \\
\hline SOR3-N & Number of Sorbus aucuparia with $\mathrm{dbh} \geqslant 3 \mathrm{~cm}$ & 0 & 0.08 & 0 & 5 \\
\hline DECI1-2 & Distance to the nearest deciduous tree with $\mathrm{dbh} 1-2 \mathrm{~cm}$ & 0 & 0.14 & 0 & 4 \\
\hline DECI1-2 N & Number of deciduous trees with dbh $1-2 \mathrm{~cm}$ & 0 & 0.13 & 0 & 11 \\
\hline DECI3- & Distance to the nearest deciduous tree with $\mathrm{dbh} \geqslant 3 \mathrm{~cm}$ & 0 & 0.12 & 0 & 4 \\
\hline DECI3-N & Number of deciduous trees with $\mathrm{dbh} \geqslant 3 \mathrm{~cm}$ & 0 & 0.07 & 0 & 3 \\
\hline CONI3- & Distance to the nearest coniferous tree with $\mathrm{dbh} \geqslant 3 \mathrm{~cm}$ & 0 & 0.12 & 0 & 3 \\
\hline CONI3-N & Number of coniferous trees with $\mathrm{dbh} \geqslant 3 \mathrm{~cm}$ & 0 & 0.08 & 0 & 3 \\
\hline LITTER & The amount of litter within a $10 \mathrm{~cm}$ radius & 0 & 0.45 & 0 & 1 \\
\hline VEGET & Coverage of forest floor vegetation (classes $1-4^{b}$ ) & 4 & 2.72 & 0 & 4 \\
\hline CANOPY & Canopy cover of dominant trees (classes $1-3^{\mathrm{c}}$ ) & 2 & 2.22 & 0 & 3 \\
\hline PATHM & Distance to the nearest medium-sized, worn path $^{\text {d }}$ & 1 & $\begin{array}{l}2.22 \\
1.40\end{array}$ & 0 & 4 \\
\hline PATHW & Distance to the nearest wide, very worn path ${ }^{\mathrm{e}}$ & 0 & 1.31 & 0 & 4 \\
\hline DEADSUM & Sum of the dbhs of dead standing trees & 0 & 0.02 & 0 & 3.7 \\
\hline DOWDIS & Distance to the nearest downed log & 0 & 0.16 & 0 & 4 \\
\hline DOWD & Diameter of downed $\log (\mathrm{m})$ & 0 & 0.01 & 0 & 1.85 \\
\hline DOWH & Height of downed $\log (\mathrm{m})$ & 0 & 0.02 & 0 & 2.5 \\
\hline DOWDEC & Decay class ${ }^{f}$ of downed log & 0 & 0.15 & 0 & 5 \\
\hline STUH1-6 & Distance to the nearest highly decayed (class $3-5$ ) stump, diameter $1-6 \mathrm{~cm}$ & 0 & 0.04 & 0 & 3 \\
\hline STUH7- & Distance to the nearest highly decayed (class $3-5$ ) stump, diameter $\geqslant 7 \mathrm{~cm}$ & 0 & 0.02 & 0 & 4 \\
\hline STUS1-6 & Distance to the nearest slightly decayed (class $1-2$ ) stump, diameter $1-6 \mathrm{~cm}$ & 0 & 0.12 & 0 & 3 \\
\hline STUS7- & Distance to the nearest slightly decayed (class $3-5$ ) stump, diameter $\geqslant 7 \mathrm{~cm}$ & 0 & 0.01 & 0 & 3 \\
\hline STUDSUM & Sum of the diameters of all stumps (m) & 0 & 0.19 & 0 & 8.2 \\
\hline STUIND & $\sum($ stump diameter $\times$ decay class $)$ & 0 & 0.08 & 0 & 3.98 \\
\hline CWD H & Distance to the nearest highly decayed (class $3-5$ ) log or stump & 1 & 1.18 & 0 & 4 \\
\hline CWD S & $\begin{array}{l}\text { Distance to the nearest slightly decayed (class } 1-2 \text { ) log, stump or dead standing } \\
\text { tree }\end{array}$ & 1 & 1.17 & 0 & 4 \\
\hline STO1-19 & Distance to the nearest stone with height $1-19 \mathrm{~cm}$ & 0 & 0.13 & 0 & 4 \\
\hline STO20- & Distance to the nearest stone with height $\geqslant 20 \mathrm{~cm}$ & 1 & 1.12 & 0 & 4 \\
\hline STODSUM & Sum of the diameters of stones (m) & 0 & 0.12 & 0 & 4.86 \\
\hline WI & Wear index (width of the nearest path $\times$ wear class) ${ }^{\mathrm{g}}$ & 0 & 0.05 & 0 & 2 \\
\hline WIP & Wear index for the $30-\mathrm{m}^{2}$ sample plot $\left.\left(\sum \text { (path area } \times \text { wear class }\right)^{\mathrm{h}}\right)$ & 0.02 & 0.07 & 0 & 1.16 \\
\hline WIC & Wear index for the study site $\left.\left(\sum \text { (path area } \times \text { wear class }\right)^{\mathrm{i}}\right)$ & 0.29 & 0.63 & 0 & 5.38 \\
\hline
\end{tabular}

${ }^{a}$ Ribes alpinum, $R$. nigrum, Rubus idaeus, Salix cinerea or Sambucus racemosa.

$\mathrm{b}_{1}=$ sparse cover $(<50 \%)$, only bottom-layer vegetation. $2=$ dense cover $(\geqslant 50 \%)$, only bottom-layer vegetation. $3=$ sparse fieldlayer vegetation $(<50 \%)$, with or without bottom-layer vegetation. $4=$ dense field layer $(\geqslant 50 \%)$, with or without bottom-layer vegetation.

${ }^{\mathrm{c}} 1=$ in an opening in the canopy, at least of the size of a canopy tree. $2=$ in a small inter tree gap. $3=$ under the canopy.

${ }^{\mathrm{d}}$ Width $20-115 \mathrm{~cm}$, vegetation clearly reduced in amount but not completely worn out. ${ }^{\mathrm{e}}$ Width $40-600 \mathrm{~km}$, mostly no vegetation left on the trail, sometimes humus layer or even mineral soil erosion.

${ }_{\mathrm{f}}$ Decay classes (1-5). 1 = Bark not fallen off, wood still hard; the knife penetrates only a few mm into the wood. $2=$ Bark not fallen off, wood still quite hard; the knife penetrates few $\mathrm{cm}$ into the wood. 3 = Bark partly fallen off, wood soft; the knife penetrates several $\mathrm{cm}$ into the wood. 4 = Bark mainly fallen off, partly covered by vegetation, wood soft; the knife penetrates up to the handle. $5=$ Covered by vegetation, only visible as a hump on the ground, wood very soft; the knife can easily be pushed through

${ }^{\mathrm{g}}$ Classes 1-4: 1 = visible effects of wear, vegetation damaged, but only slightly reduced in cover; $2=$ visible effects of wear, vegetation damaged and reduced in cover, but not completely worn away; 3 = generally no vegetation on the path, erosion of humus layer with rocks and tree roots uncovered; 4 = bare mineral soil or a deeply eroded humus layer, no vegetation remaining and rocks and tree roots often uncovered.

${ }^{\mathrm{h}}$ Each path area was multiplied by its wear class and the resulting values summed up per sample plot.

${ }^{\mathrm{i}}$ As footnote h but summed up per study site. 


\section{Appendix B}

The microhabitat characteristic used in the OR table

(Table 3).

\begin{tabular}{|c|c|}
\hline Microhabitat & Description \\
\hline CANOPY & Under the canopy (CANOPY $=3$ in Appendix A) \\
\hline VEGET & In full vegetation cover (VEGET $=4$ in Appendix A) \\
\hline ON PATH & On a path of any level of wear \\
\hline PATHLM & $\begin{array}{l}\text { Beside (within a } 50 \mathrm{~cm} \text { distance from) narrow to medium sized }(20-115 \mathrm{~cm} \text { wide) paths with light to moderate } \\
\text { wear (incl. PATHM }=1-3 \text { in Appendix A plus paths with visible signs of wear but only a slight reduction in } \\
\text { vegetation cover) }\end{array}$ \\
\hline PATHW & Beside very worn paths (PATHW $=1-3$ in Appendix A) \\
\hline STO1-39 & Beside stone(s) $1-39 \mathrm{~cm}$ high \\
\hline STO40- & Beside stone(s) $>39 \mathrm{~cm}$ high \\
\hline DEAD & Beside dead standing tree(s) (individuals $>200 \mathrm{~cm}$ tall) of any $\mathrm{dbh}$ \\
\hline DOW & Beside fallen $\log (\mathrm{s})$, decay classes $2-5$ included (DOWDEC $=2-5$ in Appendix A) \\
\hline STUH & Beside highly decayed stump(s) ((STUH1-6) + (STUH7-) in Appendix A) \\
\hline STUS & Beside slightly decayed stump(s) ((STUS1-6) + (STUS7-) in Appendix A) \\
\hline TREOWN1-2 & Beside tree(s) with a dbh $1-2 \mathrm{~cm}$, of the focal species \\
\hline TREOTH1-2 & Beside tree(s) with a dbh $1-2 \mathrm{~cm}$ of other but the focal species \\
\hline TREOWN3-9 & Beside tree(s) with a dbh $3-9 \mathrm{~cm}$, of the focal species \\
\hline TREOTH3-9 & Beside tree(s) with a dbh $3-9 \mathrm{~cm}$, of other but the focal species \\
\hline TREOWN10- & Beside tree(s) with a dbh $>10 \mathrm{~cm}$, of the focal species \\
\hline TREOTH10- & Beside tree(s) with a dbh $>10 \mathrm{~cm}$, of other but the focal species \\
\hline POP3- & Beside Populus tremula tree(s) with a dbh $\geqslant 3 \mathrm{~cm}$ \\
\hline BUSHES & Beside a bush (BUSHES $=1-3$ in Appendix A) \\
\hline SAPLOWN & Beside another sapling of the focal species \\
\hline SAPLOTH & Beside another sapling, of other but the focal species \\
\hline NOSAPLING & No other saplings within a $50 \mathrm{~cm}$ distance \\
\hline
\end{tabular}

\section{References}

Aaltonen, V.T., 1942. Muutamia kasvukokeita puuntaimilla (Experiments in the growing of forest tree seedlings). Acta Forestalia Fennica 50 (6), 1-33 (In Finnish).

Atkinson, M.D., 1992. Betula pendula Roth (B. verrucosa Ehrh.) and B. pubescens Ehrh. Biological flora of the British Isles No. 175. Journal of Ecology 80, 837-870.

Backmeroff, C.E., Peterken, G.F., 1988. Long-term changes in the woodlands of Clairinsh. Transactions of the Botanical Society of Edinburg 45, 253-297.

Beckage, B., Clark, J.S., Clinton, B.D., Haines, B.L., 2000. A long-term study of tree seedling recruitment in Southern Appalachian forests: the effects of canopy gaps and shrub understories. Canadian Journal of Forest Research 30, 1617-1631.

Bhuju, D.R., Ohsawa, M., 1998. Effects of nature trails on ground vegetation and understory colonisation of a patchy remnant forest in an urban domain. Biological Conservation $85,123-135$.

Boettcher, S.E., Kalisz, P.J., 1990. Single-tree influence on soil properties in the mountains of eastern Kentucky. Ecology 7, 1365-1372.

Carlisle, A., Brown, A.H.F., 1968. Biological flora of the British Isles No. 33 Pinus-sylvestris L. Journal of Ecology 56, 269-307.

Collett, D., 1991. Modelling Binary Data. Chapman \& Hall, London.
Collins, S.L., Good, R.E., 1987. The seedling regeneration niche: habitat structure of tree seedlings in an oak-pine forest. OIKOS 48, 89-98.

Christensen, R., 1990. Log-Linear Models. Springer, New York.

Greene, D.F., Zasada, J.C., Sirois, L., Kneeshaw, D., Morin, H., Charron, I., Simard, M.-J., 1999. A review of the regeneration dynamics of North American boreal forest tree species. Canadian Journal of Forest Research 29, 824-839.

Grubb, P.J., 1977. The maintenance of species-richness in plant communities: the importance of the regeneration niche. Biological Reviews 52, 107-145.

Hämet-Ahti, L., Palmén, A., Alanko, P., Tigerstedt, P.M.A., 1992. Suomen puu- ja pensaskasvio (Woody Flora of Finland). Dendrologian Seura, Helsinki (In Finnish).

Harper, J.L., 1977. Population Biology of Plants. Academic Press, London.

Helsinki Region Statistics, 1998. http://heln03.novogroup.com/asarjat/(October 2003).

Hofgaard, A., 1993. Structure and regeneration patterns of a virgin Picea abies forest in northern Sweden. Journal of Vegetation Science 4, 601-608.

Hytteborn, H., Packham, J.R., Verwijst, T., 1987. Tree population dynamics, stand structure and species composition in the montane virgin forest of Vallibäcken, northern Sweden. Vegetatio 72, 3-19. 
Jongman, R.H.G., Ter Braak, C.J.F., van Tongeren, O.F.R. (Eds.), 1995. Data Analysis in Community and Landscape Ecology, 2nd Edition. Cambridge University Press, Cambridge.

Jonsell, B., Karlsson, T. (Eds.), 2000. Flora Nordica vol. 1 Lycopodiaceae to polygonaceae. The Bergius Foundation. The Royal Swedish Academy of Sciences, Stockholm.

Jonsson, B., 1999. Stand establishment and early growth of planted Pinus sylvestris and Picea abies related to microsite conditions. Scandinavian Journal of Forest Research 14, 425-440.

Jumpponen, A., Väre, H., Mattson, K.G., Ohtonen, R., Trappe, J.M., 1999. Characterization of 'safe sites' for pioneers in primary succession on recently deglaciated terrian. Journal of Ecology 87, 98-105.

Kalela, E.K., 1942. Männyn taimien juurien suhtautumisesta emäpuun juuriin. Acta Forestalia Fennica 50 (17), 1-12 (In Finnish, with German summary).

Kaplan, R., Kaplan, S., 1989. The Experience of Nature. A Psychological Perspective. Cambridge University Press, New York.

Kellomäki, S., 1977. Potential of trails in guiding recreational activity. Silva Fennica 11, 263-268 (In Finnish, with English summary).

Kubota, Y., 2000. Spatial dynamics of regeneration in a conifer/broad-leaved forest in northern Japan. Journal of Vegetation Science 11, 633-640.

Kubota, Y., Hara, T., 1996. Recruitment process and species coexistence in sub-boreal forest in Northern Japan. Annals of Botany 78, 741-748.

Kuuluvainen, T., 1994. Gap disturbance, ground microtopography, and the regeneration dynamics of boreal coniferous forests in Finland: a review. Annales Zoologici Fennici 31, $35-51$.

Kuuluvainen, T., Juntunen, P., 1998. Seedling establishment in relation to microhabitat variation in a windthrow gap in a boreal Pinus sylvestris forest. Journal of Vegetation Science 9, 551-562.

Kuuluvainen, T., Hokkanen, T.J., Järvinen, E., Pukkala, T., 1993. Factors related to seedling growth in a boreal Scots pine stand: a spatial analysis of a vegetation-soil system. Canadian Journal of Forest Research 23, 2101-2109.

Laitakari, E., 1927. The root system of pine (Pinus sylvestris), a morphological investigation. Acta Forestalia Fennica 33, 1-380 (In Finnish, with English summary).

Leather, S.R., 1996. Biological flora of the British Isles, Prunus padus L. Journal of Ecology 84, 125-132.

LeDuc, M.G., Havill, D.C., 1998. Competition between Quercus petraea and Carpinus betulus in an ancient wood in England: seedling survivorship. Journal of Vegetation Science 9, 873-880.

Leemans, R., 1991. Canopy gaps and establishment patterns of spruce (Picea abies (L.) Karst.) in two old-growth coniferous forests in central Sweden. Vegetatio 93, 157-165.
Lehvävirta, S., 1999. Trampling and urban forest structure. Urban Ecosystems 3, 45-56.

Lehvävirta, S., Rita, H., 2002. Natural regeneration of trees in urban woodlands. Journal of Vegetation Science 13, 57-66.

Liddle, M.J., 1997. Recreation Ecology: The Ecological Impact of Outdoor Recreation and Ecotourism. Chapman \& Hall, London.

Livingston, R.B., 1972. Influence of birds, stones and soil on the establishment of juniper, Juniperus communis and red cedar, J. virginiana, in New England pastures. Ecology 53, 1141-1147.

Nakashizuka, T., 1989. Role of uprooting in composition and dynamics of an old-growth forest in Japan. Ecology 70, 1273-1278.

Narukawa, Y., Yamamoto, S., 2001. Gap formation, microsite variation and the conifer seedling occurrence in a subalpine old-growth forest, central Japan. Ecological Research 16, 617-625.

Perala, D.A., Alm, A.A., 1990. Reproductive ecology of birch: a review. Forest Ecology and Management 32, 1-38.

Platt, W.J., Strong, D.R. (Eds.), 1989. Special featureTreefall gaps and forest dynamics. Ecology 70(3), 535-576.

Qinghong, L., Hytteborn, H., 1991. Gap structure, disturbance and regeneration in a primeval Picea abies forest. Journal of Vegetation Science 2, 391-402.

Sernander, R., 1936. Granskär och Fiby urskog. (The primitive forests of Granskar and Fiby: a study of the part played by storm-gaps and dwarf trees in the regeneration of the Swedish spruce forest). Acta Phytogeographica Suecica 8 (In Swedish with English summary).

Taylor, A.H., Zisheng, Q., 1988. Regeneration patterns in oldgrowth Abies-Betula forests in the Wolong natural reserve, Sichuan, China. Journal of Ecology 76, 1204-1218.

Ter Braak, C.J.F., Šmilauer, P., 1998. Canoco for Windows Version 4.0. Centre for Biometry, Wageningen.

Tonnesen, A.S., Ebersole, J.J., 1997. Human trampling effects on regeneration and age structures of Pinus edulis and Juniperus monosperma. Great Basin Naturalist 57 (1), $50-56$.

Ward, J.S., Parker, G.R., 1989. Spatial dispersion of woody regeneration in an old-growth forest. Ecology 70, 1279-1285.

Weiner, J., 1984. Neighbourhood interference amongst Pinus rigida individuals. Journal of Ecology 72, 183-195.

Whitmore, T.C., 1989. Canopy gaps and the two major groups of forest trees. Ecology 70, 536-538.

Wright, E.F., Canham, C.D., Coates, K.D., 2000. Effects of suppression and release on sapling growth for 11 species of northern, interior British Columbia. Canadian Journal of Forest Research 30, 1571-1580.

Yli-Vakkuri, P., 1963. Experimental studies on the emergence and initial development of tree seedlings in spruce and pine stands. Acta Forestalia Fennica 75, 1-110 (In Finnish, with English summary). 